\title{
Design and Implementation of Management Platform for Undergraduate Thesis
}

\author{
Jinghui Wang ${ }^{1, a,{ }^{*}}$, Hao Cui ${ }^{1, b}$, Yu Han ${ }^{1, c}$, \\ Wei Cao ${ }^{1, d}$, Yanyu Zang ${ }^{1, e}$ and Runmeng Qin ${ }^{1, f}$ \\ 1 Jilin Agricultural University, Changchun 130118, Jilin, China \\ a346056461@qq.com, b1874142898@qq.com, '781945719@qq.com,

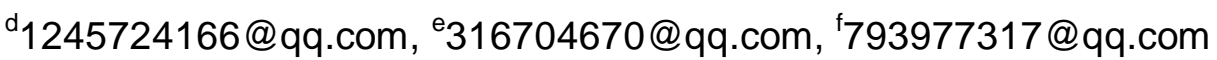

\section{Keywords: Graduation thesis; Management platform; Design; Implementation}

\begin{abstract}
In order to improve the management efficiency of undergraduate theses, J2EE, SQL Server2005 and other technologies were used to develop the management platform of undergraduate thesis. This management platform includes system maintenance, student management, teacher review and query statistics module, and provides user registration, authentication, online topic selection, online paper submitting, performance evaluation and system management functions. Thus, the network management of graduation thesis in the whole process from the proposal to the quality evaluation can be realized. And the quality of teaching management can be improved effectively.
\end{abstract}

\section{Introduction}

Undergraduate thesis management is a very important part of talents cultivation and undergraduate teaching. Through the investigation, at present, many colleges and universities adopt traditional manual mode to manage undergraduate thesis [1]. However, there are many problems in it. It spends long time to select a topic, propose a thesis, modify theses, archive and consult theses, resulting in low working efficiency[2-4]. Because of the heavy management task and other problems, the quality of graduation thesis can't be guaranteed [5]. In the environment of the Internet network, with the development of modern undergraduate education model, it is particularly important to develop an undergraduate thesis management platform to adapt to the development trend of colleges and universities [6].

\section{System Analysis}

Demand Analysis. The service target of undergraduate thesis management platform is the teaching management staff (reviewer), teachers and graduating students [7]. The system should grant different permissions to the three types of users and enable them to log in from the foreground [8-10]. The teacher submits the thesis titles to the background, and then after they are reviewed by the reviewer, they are put into the database. Students enter the system according to their own login account. After entering the system, they can see these thesis titles. Students should select the appropriate topic according to their actual situation. When a topic selection exceeds the set number, they can't select it. When students have selected the topics, they should directly contact with their instructors to complete their thesis proposals and submit them. After teachers confirm that students can propose the thesis, students can make the graduation design. And then they should submit the graduation theses and prepare for the graduation reply. Each student's defense record material and defense results will be placed in the database.

System Functional Analysis. The management platform of an undergraduate thesis is divided into foreground and background management section. Foreground section includes user registration, graduation thesis submitting, thesis proposal submitting, information browsing and other operations. In the background management section, the user initialization information can be put into the database, graduation thesis situation can be browsed, the graduation thesis topics can be reviewed and put into the database and also the defense record and results can be put into the database. 


\section{System Design}

The undergraduate thesis management platform is divided into six modules, including system maintenance module, student management module, teacher review module, query statistics module and system safety management. The structure of the platform module is shown in Fig. 1.

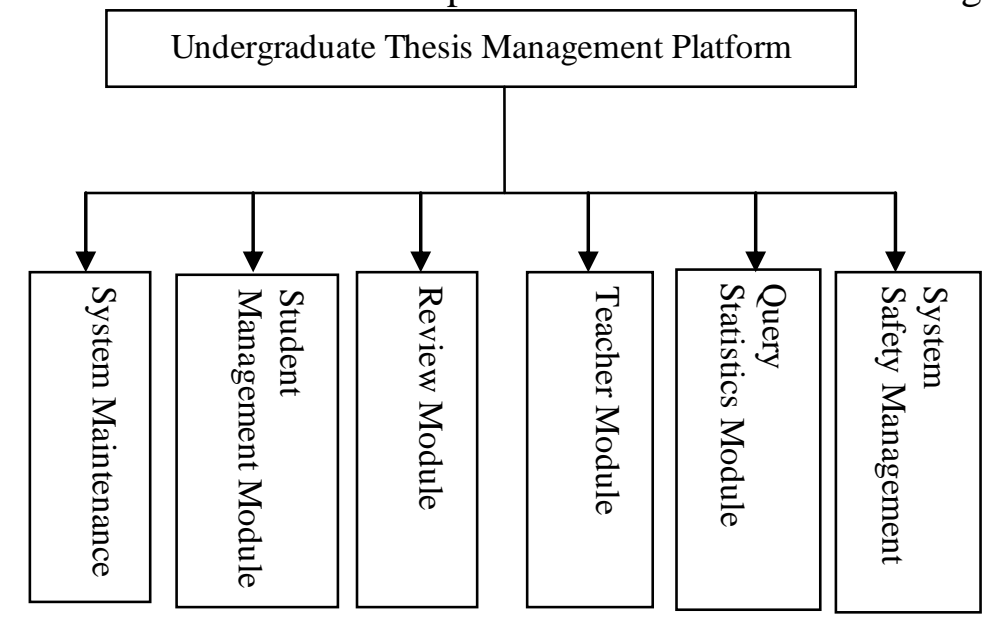

Figure 1. The structure chart of platform module

System Maintenance Module. The main functions include the configuration of system parameters, backups of the system database and disaster recovery.

Student Management Module. The main users are graduating class students. The functions of it include theses and requirements query, online topic selecting, online thesis proposal submitting, online graduation thesis submitting.

Teacher Module. This module is used by teachers. The functions of it include online submission of thesis topics and requirements, the check of students' topic selection situation, the review of student's thesis proposal, interim report and graduation thesis.

Review Module. The users are the director of the teaching-research section and the teaching secretary. The functions of it are that the reviewers can review teachers' thesis topics and thesis requirements, release the qualified thesis topics online for students to select, review students' thesis proposals, interim reports and theses, put the qualified thesis proposals, interim reports and theses into the database and archive them.

Query Statistics Module. In fact, the teacher module and student module both provide the query function, but this module is mainly used to query the thesis and thesis proposal, which have been archived.

System Safety Management. It is used to establish a user account and distribute user permission.

\section{Realization of System Function}

System Development Tools. J2EE platform and Struts, Hibernate and Tomcat technologies are used to establish a distributed management system. Struts+Hihernate technology is adopted to realize the hierarchical division of WEB application and the operation of the database.

The Implementation of the Main Functional Module. The reviewer has achieved the following functions. The interface is shown in Fig. 2.

The first one is the distribution of login information of teachers and students. The reviewer mainly distributes the login permission for teachers and students. In order to facilitate the management and prevent the login of non graduate and other users, students can't be allowed to register personally. The login permission of students must be distributed by reviewers. And then the reviewer imports the student information into the database uniformly. The second one is to browse the topic selection situation of students. This feature mainly browses the students who have chosen the paper. Through the combination inquiry table, the reviewer first finds the corresponding topic number of student's name in the student table, and then, according to the topic number, finds the corresponding thesis title, teacher's name and other relevant information in the question bank table. The third one is to browse and review 
theses and put the theses into the database. When all papers submitted by teachers are shown, the reviewer will check the specific requirements and instructions of the paper and review whether the papers meet the requirements. If approved, it will be published, but the paper which is in the released state will not be released. Teachers and students can only see papers published by reviewers when they $\log$ in. The fourth one is to put the defense record and results into the database. After the defense, the reviewer will put students' results into the database and engrave the relevant materials of students' theses on the CD. Then the reviewer should upload the defense record to the specified folder in the form of Word documents and record the relative path of this file to ensure the download and facilitate the future inspection of students' defense record. The fifth one is the query statistics. This function mainly achieves the query of the defense record and defense results of students' theses, and the statistics of the number of students guided by teachers. The teacher who guide the excellent papers will be given the allowance and the data can be checked in the software.

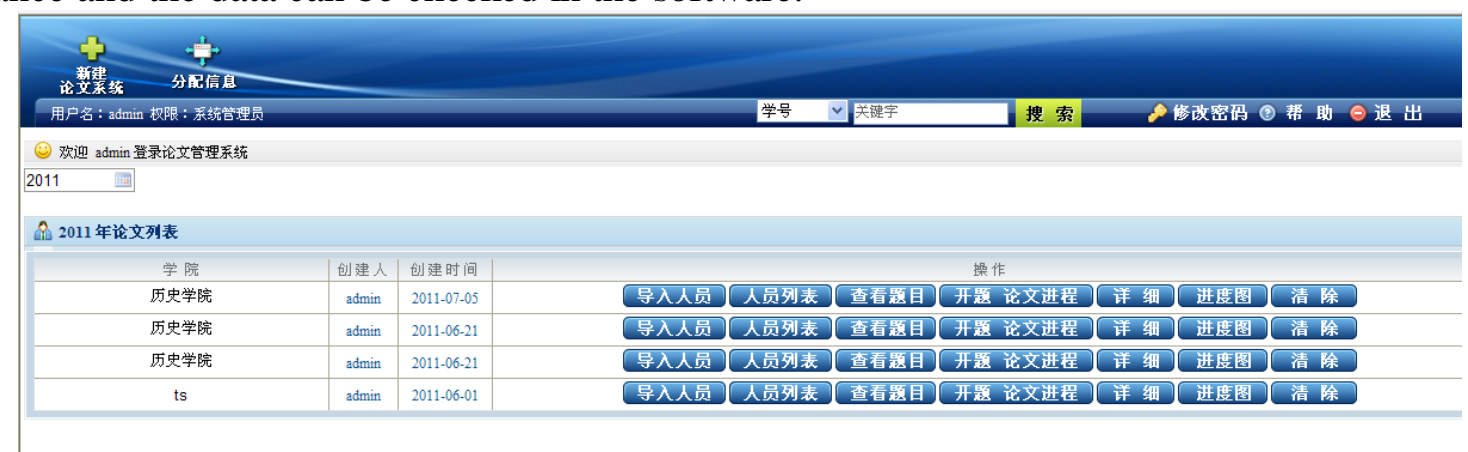

Figure 2. The main interface of the reviewer function

The teachers have achieved the following functions. The interface is shown in Fig. 3.

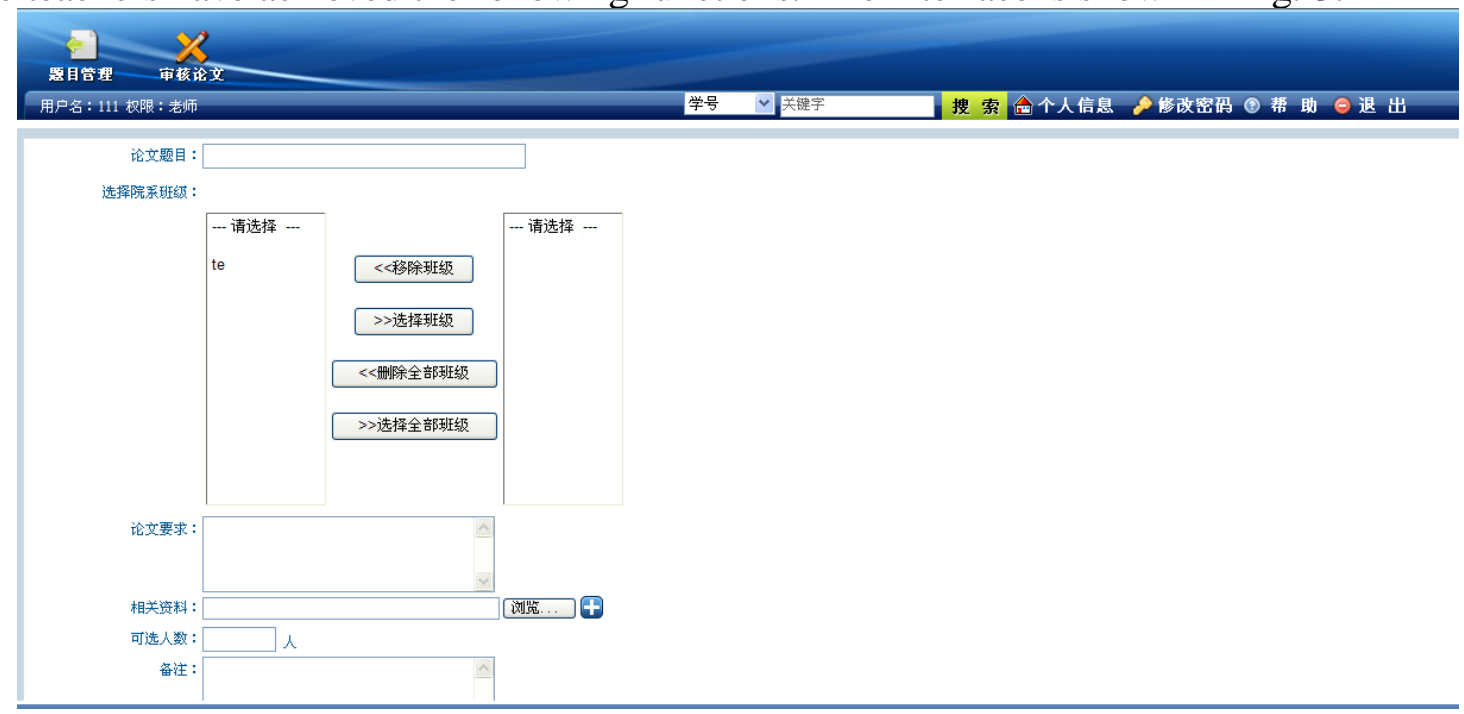

Figure 3. Teachers function interface

The first one is to submit theses. The main function is that teachers can upload their thesis topics, relevant thesis information and thesis requirement documents and submit them to the database. After they are reviewed by the reviewer, they can be released. The second one is to browse theses. Teachers can browse the thesis topics and the relevant information submitted by reviewers and download the thesis topic. The third one is to check the situation of students who have chosen the papers. Teachers can browse the situation of students who have chosen the thesis topics and understand the situation of thesis topics chosen by students in order to guide students to propose, design and write theses. The fourth one is to download students' thesis proposals and graduation theses. The main function is that teachers can download students' thesis proposals and graduation theses. Thus, the teacher can check their contents and guide students to revise the thesis proposals and graduation theses.

The students have achieved the following functions. The interface is shown in Fig. 4.

The first one is to browse the thesis topics. After entering the system through their own accounts, students browse the approved titles. And then they select the appropriate topic according to their own 
situations. When a topic selection exceeds the set number, they can't select it. The second one is to submit the thesis proposal. When students have selected the topics, they can contact with their instructors to complete their thesis proposals and submit them. After the teachers confirm that students can propose the thesis, students can make the graduation design. The third one is to submit the graduation thesis. When students have completed the graduation theses, they can submit them to the background through the network. The fourth one is to download the relevant materials. Students can download the relevant materials needed in the course of graduation design and graduation thesis writing.

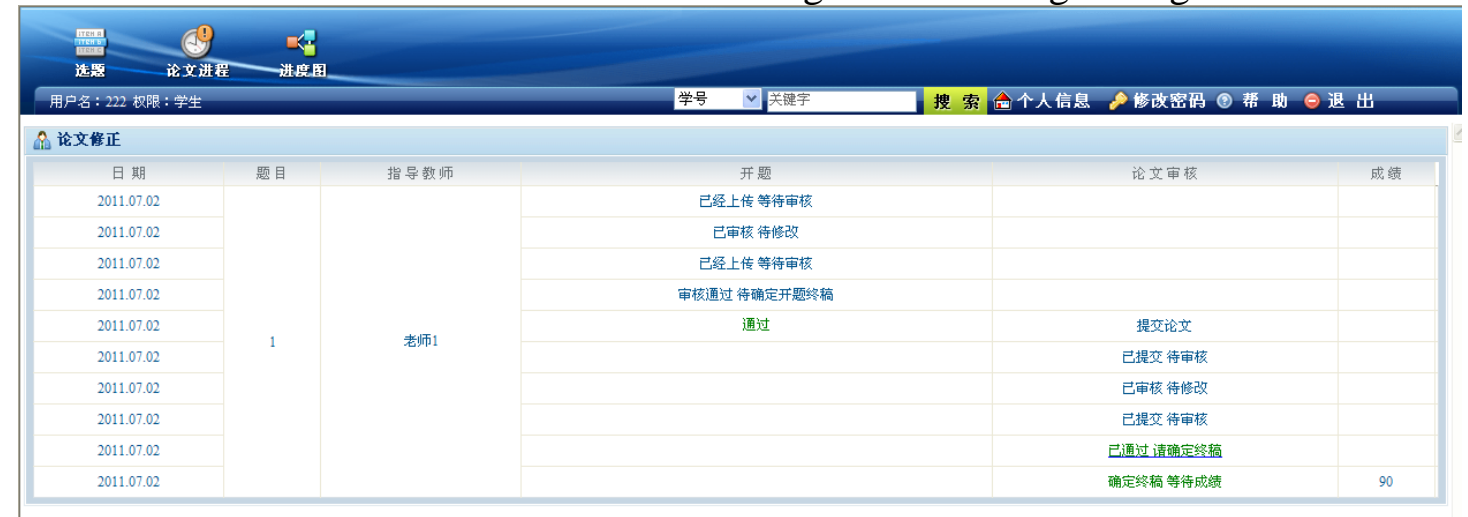

Figure 4. Student function interface

\section{System Testing}

In order to ensure the correctness of the platform function and logic, developers adopt the basic idea of traditional software testing, black box testing and white box testing [11-14]. And combined with the techniques used in platform development, they make the static testing, dynamic testing and the testing based on WEB system for the management platform of undergraduate thesis. In addition, they have made the link testing, form testing, Cookies testing, design language testing and database testing from the perspective of platform function. From the perspective of platform performance, they make the connection speed testing, load testing, stress testing and navigation testing. From the perspective of the platform usability, they make the navigation testing, figure testing, content testing and whole interface testing. From the perspective of the client compatibility, they make the platform testing and browser testing. Finally, they test from the perspective of security. According to the testing results, the correctness of system function and logic can be verified.

\section{Conclusion}

The management platform of undergraduate thesis based on Internet network environment is conducive to improving the working efficiency, solves the problems that graduates can't communicate with teachers face to face in the course of internship and provides a good environment and working platform for supervising and reviewing the graduation theses. This management platform adds some new contents for improving the management model of traditional theses and plays an active role in improving the quality of talent cultivation. It is not only an important means to realize the teaching management's modernization and network, but also to promote the reform of teaching mode. Also, it has a very important significance and practical value for improving the teaching management and teaching quality.

\section{Acknowledgements}

The authors wish to express their gratitude to the projects: "12th Five-Year" Education and Science Planning Subjects of Jilin Province (No. GH150208) and "12th Five-Year" Social Science Research Planning Project for their generous support of this work. 


\section{References}

[1] F.H.Wang, H.Chen and X.H.Wang: Higher Education Forum, 2011, No.7, p.99. (In Chinese)

[2] R.H.Zhu: Journal of Henan Radio \& TV University, Vol.24 (2011), No.2, p.93. (In Chinese)

[3] J.D.Wang: Journal of Guizhou Radio \& TV University, Vol.21 (2013), No.2, p.16. (In Chinese)

[4] J.G.Zeng and G.Luo: Journal of Chengdu Technological University, Vol.16 (2013), No.2, p.18. (In Chinese)

[5] W.J.Cai: Journal of Hubei University of Science and Technology, Vol.34 (2014), No.7, p.158. (In Chinese)

[6] L.Fang: Journal of Jilin Agricultural Science and Technology University, Vol.23 (2014), No.3, p.93. (In Chinese)

[7] X.N.Zhang and X.G.Zhang: Journal of Ningbo University of Technology, Vol.26 (2014), No.1, p.103. (In Chinese)

[8] S.Wang and S.G.Chen: Journal of Fuyang Teachers College, Vol.32 (2015), No.1, p.62. (In Chinese)

[9] R.H.Wu: Journal of Huaihua University, Vol.34 (2015), No.6, p.123. (In Chinese)

[10] Y.L.Jin: Journal of Qiqihar Institute of Engineering, Vol.9 (2015), No.3, p.59. (In Chinese)

[11] L.Chen: Journal of Hubei University of Education, Vol.33 (2016), No.10, p.94. (In Chinese)

[12] L.Guo and Y.M.Fan: Journal of Linyi University, Vol.38 (2016), No.3, p.115. (In Chinese)

[13] R.J.Li: Journal of Chifeng University, Vol.32 (2016), No.6, p.243. (In Chinese)

[14] S.Y.Song: Journal of Yuxi Normal University, Vol.33 (2017), No.4, p.62. (In Chinese) 